REVISTA X, Curitiba, volume 12, n.3, p.131-151,2017.

\title{
GOOD LUCK OR BAD LUCK? UMA AULA DE LEITURA NA TELA EM LÍNGUA INGLESA
}

\section{Good luck or bad luck? An English reading lesson on the screen}

\author{
Marilane de Abreu Lima MIRANDA - UFMG ${ }^{1}$ \\ Patrícia Mara de Carvalho COSTA LEITE - UFMG ${ }^{2}$
}

\begin{abstract}
RESUMO: Este artigo apresenta a construção e a análise de uma aula de língua inglesa para o oitavo ano, em um grupo de 35 alunos, realizada em uma escola pública em uma pequena cidade de Minas Gerais, cujo foco é o ensino de leitura em tela. Nossas perguntas de pesquisa são: Há alguma inovação trazida pelo projeto para a sala de aula? Que contribuições ele oferece para o ensino de leitura? Para tanto desenvolvemos uma aula sobre "superstições", baseada no tópico oferecido pelo livro didático adotado pela escola e ancorada nas teorias sobre leitura, língua/linguagem e letramento de Coscarelli e Cafiero (2013), Soares (2010), Kleiman (2004) e Bräkling (2004), notadamente. Posteriormente, aplicamos um questionário para o professor e um para os alunos, a fim de obtermos um feedback do processo. Os resultados evidenciam que a leitura em tela pode atrair a atenção dos alunos, motivando-os a lerem mais, tanto na tela quanto no papel e que as estratégias de leitura contribuem para a compreensão do texto, bem como para derrubar possíveis barreiras em relação à leitura do texto em língua inglesa.
\end{abstract}

PALAVRAS-CHAVE: aula de língua inglesa; ensino de leitura em tela; estratégias de leitura

ABSTRACT: This article presents the analysis of an English lesson, which aims at teaching reading on screen, delivered in the eighth grade to a group of 35 students at a State School in a small city of Minas Gerais. The research questions are: Is there any innovation brought by the project to the classroom? What are the contributions that this study offers to the teaching of reading? We developed a lesson on "superstitions", based on the topic of the textbook used at school and supported by the theories on reading, language and literacy, mainly by Coscarelli e Cafiero (2013), Soares (2010), Kleiman (2004) e Bräkling (2004). Then, we asked both teachers and students to answer a questionnaire to get feedback on this lesson. The outcomes emphasize that reading on screen not only attracts students' attention but also motivates them to read more, on screen or paper, and that the reading strategies contribute to the comprehension of the text as well as to overcome barriers regarding reading the text in English.

KEYWORDS: English lesson; teaching screen reading; reading strategies

\begin{tabular}{|c|c|c|c|c|c|c|c|}
\hline $\begin{array}{l}1 \quad \text { Doutoranda em Estudos } \\
\text { mewwaycourse@gmail.com }\end{array}$ & Linguísticos & na & Universidade & Federal & de & Minas & Gerais. \\
\hline $\begin{array}{l}2 \text { Doutoranda em Estudos } \\
\text { patriciamccostaleite@gmail.com }\end{array}$ & Linguísticos & na & Universidade & Federal & de & Minas & $\mathrm{Ge}$ \\
\hline
\end{tabular}




\section{INTRODUÇÃO}

O mundo em que vivemos, constantemente, nos bombardeia com informações de todos os tipos, seja por meio da internet, de outdoors, de placas, propagandas, grafites, cartazes, anúncios, para mencionar alguns. Para que possamos ter uma “ampliação da participação social e exercício efetivo da cidadania” (BRÄKLING, 2004, p. 1) precisamos de uma formação eficiente de leitores, notoriamente no ambiente escolar. Isso implica em formar leitores que sejam capazes de ir além do que está escrito, capazes de inferir significado, incorporar o que há nos textos a fim de transformar seu próprio conhecimento, questionando, duvidando, dialogando com o texto. Enfim, "uma formação que lhe permita compreender criticamente as realidades sociais e nela agir, sabendo, para tanto, organizar sua ação” (BRÄKLING, 2004, p. 1).

" $\mathrm{Na}$ atualidade, as demandas sociais de leitura e escrita têm exigido dos sujeitos capacidades de letramento cada vez mais avançadas" (BARROS, 2009, p. 161). A autora faz alusão à necessidade de se ensinar a leitura tanto do verbal quanto do imagético já que "todos os textos são multimodais, a língua tem de ser realizada por meio de (...) outros modos semióticos" (KRESS; VAN LEUWEEN, 1998 apud RIBEIRO, 2013, p. 65). Barros (2009, p. 165/166) acredita que "o sistema humano de processamento de informações possui dois canais: um para o material verbal e outro para o material visual (...) uma aprendizagem realmente significativa envolve uma conexão de ambos”. Ribeiro (2013) ainda chama a atenção para a mensagem de um texto que é expressa não só verbalmente, mas através de imagens, do design da página, de negritos, sublinhados, por exemplo.

Assim, é de suma importância que a escola abarque também o ensino da leitura da imagem, do layout do texto, ou seja, a leitura em uma perspectiva multimodal, para que o aluno possa fazer uso dessas pistas a fim de compreender melhor o que está sendo lido. Porém, Kleiman (2004), a partir de seus estudos, conclui que a escola ainda desloca o letramento verbal a um primeiro plano, negando a importância do letramento visual. Entendendo que a carência de se tratar o texto na perspectiva multimodal ainda existe, priorizamos a leitura em tela, tanto do material verbal quanto do visual, conduzindo a presente pesquisa em uma escola pública de uma cidade do interior de Minas Gerais. 
O tópico da aula originou-se da análise do livro didático adotado pela turma, Alive! 8 (PAIVA; BRAGA; FRANCO, 2012), que apresenta um capítulo sobre superstições, a unidade 8 , com o qual a professora estava trabalhando no momento em que apresentamos a proposta. A pesquisa foi conduzida em uma escola estadual de uma cidade com pouco mais de 15.000 habitantes, segundo dados do $\mathrm{IBGE}^{3}$.

Nosso objetivo geral de pesquisa é perceber se a leitura em tela, dentro da escola pública em questão, é uma inovação, bem como, motivar os alunos a ler mais e a usar estratégias de leitura para fazê-la de maneira mais proveitosa e eficiente.

Por meio da aula de leitura por nós elaborada, visamos: verificar as contribuições do material para a formação do leitor; a participação e o envolvimento dos alunos nas atividades; identificar a reação e a opinião do professor à aula dada; certificar se a leitura em tela motiva o aluno; se o professor da turma já faz uso da leitura em tela; se o aluno gosta do suporte da tecnologia e incentivar o professor da classe a continuar com o trabalho de estratégias de leitura.

Nossa análise pode oferecer subsídios para aulas posteriores tanto na leitura do impresso quanto em tela. Podemos também chamar a atenção tanto dos alunos quanto dos professores para a eficácia do uso de estratégias de leitura, já que acreditamos que "através do ensino explícito de estratégias, o professor exerce o papel de mediador no processo de capacitação do leitor proficiente" (SANTORUM; SCHERER, 2008, p. 1).

O artigo está organizado em quatro seções, além da introdução, considerações finais, referências e apêndice, a saber: iniciamos com concepções primordiais ao nosso estudo, tais como: de linguagem/língua, leitura, letramento e aprendizagem declaradas na proposta das atividades da aula; posteriormente, discutimos as contribuições das atividades para a leitura; analisamos os questionários aplicados em relação à contribuição e inovação trazidas pela atividade pelo prisma do professor e dos alunos; finalmente, analisamos e discutimos os dados, respondendo às duas perguntas de pesquisa: Há alguma inovação trazida pelo projeto para a sala de aula? Que contribuições trazem para a aula de leitura em língua inglesa?

\section{CONCEPÇÕES}

${ }^{3}$ Disponível em: http://cidades.ibge.gov.br/xtras/perfil.php?codmun=310230. Acesso em: 15 nov. 2016. 
As atitudes tomadas em relação ao modo de se ensinar, no caso, a leitura, têm respaldo nas concepções de texto, língua/linguagem, leitura que temos. Desse modo, Coscarelli e Cafiero (2013, p. 11) ressaltam que “(1) o professor não ensina errado- são as teorias que possui que o orientam, mas as teorias mudam, ampliam-se e nem sempre as contribuições de um novo olhar teórico são incorporadas a sua prática; (2) o aluno não é incapaz- precisa aprender a lidar com um processo (...) ensinado por meio de estratégias”. É primaz, pois, que estabeleçamos as concepções de língua/linguagem, leitura, letramento e aprendizagem declaradas nas atividades em que se baseou a construção da aula em análise.

A língua é concebida, aqui, como social e dinâmica. Ela produz discursos. A língua é um objeto sistêmico (não podemos negar a parte da materialidade, de sua forma), porém, esse sistema está cultural, social e historicamente situado; é um sistema que varia. De acordo com Coscarelli e Cafiero (2013, p. 16):

\begin{abstract}
ao se entender que a língua não é uma estrutura pronta (...) o leitor passa a ser concebido como sujeito ativo que constrói suas habilidades e conhecimentos na interação com o objeto (o texto escrito) e na interação com os outros. (...) Ensinar a ler significa levar os alunos a desenvolver uma série de habilidades cognitivas, sociais e atitudinais.
\end{abstract}

Não obstante, o trabalho de aprender a ler não é mais considerado um processo passivo em que o leitor "recebe sentidos prontos" (COSCARELLI; CAFIERO, 2013, p. 16). O leitor e o escritor se unem por meio do texto. "O texto é tomado como um todo (...) é constituído tanto por palavras, frases e períodos, quanto por recursos não verbais como as imagens, as cores e o design gráfico, que compõe seu leiaute" (Ibid., p. 16). A aprendizagem da leitura exige um ensino sistemático, como já mencionado anteriormente.

A linguagem, por sua vez, não é mais vista como expressão do pensamento, mas como interação/ discurso (KLEIMAN, 2004). É a representação de um sujeito cultural, social, e historicamente situado. Essa visão já não posiciona o autor como soberano, ou mesmo, relata que tudo está no texto. O leitor aqui é "agente da produção de sentidos (...), ou seja, o bom leitor age sobre o texto monitorando sua leitura, ou verificando se está compreendendo" (COSCARELLI; CAFIERO, 2013, p. 21).

Uma evidência desse modo de se conceber a língua/linguagem, na aula, por nós planejada, foi ensinar o vocabulário presente no texto através de seu uso na frase e no 
texto. A partir do contexto, os alunos inferiram o significado das palavras na frase. Se utilizássemos palavras soltas, partilharíamos de uma concepção estruturalista da língua, dando maior valor à forma do que ao significado ${ }^{4}$.

Para contemplar tal concepção de língua/linguagem, a leitura é abordada, aqui, como uma prática social, visto que depende da cultura, do outro, do contexto de comunicação. A situação exerce influência direta nos objetivos e usos de leitura. Bräkling (2004, p. 2) amplia esse significado declarando que ler é uma prática social visto "que acontece em diferentes espaços, que possuem características muito específicas: o tipo de conteúdos dos textos que nele circulam, as finalidades, colocadas para a leitura, os procedimentos mais comuns, decorrentes dessas finalidades, os gêneros dos textos".

A leitura é uma perspectiva social, mas também, é um processo cognitivo, individual, podendo ser ensinada, já que ela acontece por meio de operações mentais que o sujeito executa (conhecimento prévio, estratégias de leitura- inferir, relacionar, localizar). Além de ser uma prática social, um processo cognitivo e individual, a leitura também se constitui em um processo único, interpessoal e dialógico segundo Bräkling (2004, p. 4), que acrescenta ainda que

\begin{abstract}
isso nos remete diretamente à natureza do processo de leitura. Toda leitura é individual porque significa um processo pessoal e particular de processamentos de sentidos do texto. Mas toda leitura também é interpessoal porque os sentidos não se encontram no texto, exclusivamente, ou no leitor, exclusivamente; ao contrário, os sentidos situam-se no espaço intervalar entre texto e leitor. (...) Os sentidos de um texto, portanto, ao mesmo tempo em que são resultado de um processo pessoal e intransferível, dialogam, inevitavelmente com o outro: com o autor, com os outros presentes no corpo das ideias que constituía o horizonte cultural do momento da sua produção. A leitura, assim, é pessoal e, ao mesmo tempo, dialógica.
\end{abstract}

No caso de nosso estudo, consideramos o contexto em que os alunos se inserem, as características da instituição em que se encontram, suas histórias de vida. Outro ponto levado em consideração foi o uso de textos autênticos. Paiva (2005, p. 147) aconselha o uso deles e de textos simples e acrescenta "como aconselha Ur (1996, p. 149), use textos diversos para que os alunos possam praticar diferentes tipos de leitura e assegure-se que a maioria do vocabulário seja conhecida e que os alunos possam identificar facilmente as palavras desconhecidas ou, simplesmente, ignorá-las”. Assim,

\footnotetext{
${ }^{4}$ O plano de aula completo encontra-se no Apêndice 1.
} 
os textos sobre superstições e sorte foram retirados da internet com o cuidado de serem textos autênticos, que fizessem parte do universo jovem, diversos (vídeo; textos da internet; charges ${ }^{5}$ ) e também que fossem apropriados ao contexto formal de aprendizagem.

A concepção de que a leitura pode ser ensinada nos levou ao uso de estratégias como forma de ensinar os alunos a lerem e compreenderem os textos de forma efetiva (Carrell; Gajdusek; Wise, 1998 apud JOLY, 2006). As estratégias podem ser definidas como ferramentas, ações mentais, para se atingir um determinado fim. Uma pergunta pertinente seria: quais são as ações mentais que o bom leitor realiza? A partir disso, é possível propor atividades de ensino que promovam leituras mais eficientes, ou seja, não basta pedir ao aluno para ler um texto, é preciso ensinar ao aluno a ler de modo competente.

$\mathrm{Na}$ aula em questão, seguimos alguns objetivos de leitura, que envolvem estratégias específicas, a saber: pré-leitura; compreensão geral; de pontos principais; detalhada e a pós-leitura. A partir desses objetivos, selecionamos algumas estratégias de leitura baseadas nos textos de Bräkling (2004), Joly et al (2006) e Santorum; Scherer (2008): conhecimento prévio; previsão; uso de cognatos; uso de informação não verbal; compreensão geral; compreensão detalhada.

Bräkling (2004, p. 5) caracteriza um leitor competente como sendo

aquele que usa a linguagem escrita - e, portanto, a leitura - efetivamente, em diferentes circunstâncias de comunicação; é aquele que se apropriou das estratégias e dos procedimentos ${ }^{6}$ de leitura característicos das diferentes práticas sociais das quais participa, de tal forma que os utiliza no processo de (re) construção dos sentidos dos textos (negrito da autora).

Concordamos com Bräkling (2004) que o uso das estratégias de leitura e o estabelecimento do objetivo de leitura são essenciais para que a leitura do texto seja viável, relevante e prazerosa e, assim, o fizemos na aula planejada. Isso por entendermos que, muitos alunos, no contexto da aprendizagem de línguas estrangeiras, ainda recorrem à tradução literal, de modo frequente, ou mesmo, ainda temem a leitura

\footnotetext{
${ }^{5}$ A charge "Oração e ação" (Chico Bento) está disponível em: https://wordsofleisure.com/tag/chicobento/. Acesso em: 10 abr. de 2016.

${ }^{6}$ Bräkling (2004) faz uma divisão entre estratégias de leitura e procedimentos de leitura. Joly (2006); Santorum e Scherer (2008), por sua vez, só utilizam a nomenclatura estratégias. Optamos, neste estudo, por utilizarmos somente o termo estratégias que englobam os procedimentos propostos por Bräkling (2004).
} 
em outra língua, uma vez que a associam com a compreensão de todos os vocábulos do texto, sem exceção.

Finalmente, concebemos o letramento como algo além da alfabetização. Soares (2010) revela que há vários conceitos de letramento já que cada um o observa por um prisma diferente: o da antropologia, o linguístico, o da psicologia e o educacional. "Se a perspectiva é educacional, pedagógica, letramento designa as habilidades de leitura e escrita de crianças, jovens ou adultos, em práticas sociais que envolvem a língua escrita" (p. 55, itálico da autora). O letramento não é apenas o ensino da decodificação, mas uma tarefa complexa que exige trabalho.

\section{PROCEDIMENTOS E CONTRIBUIÇÕES DA AULA MINISTRADA}

Dados obtidos através de avaliações sistêmicas nacionais e internacionais como o Exame Nacional do Ensino Médio (ENEM), Sistema de Avaliação da Educação Básica (SAEB), Prova Brasil e PISA demonstram que o ensino de leitura precisa ser melhor trabalhado (COSCARELLI; CAFIERO, 2013). Outro fator preocupante sobre o ensino de leitura que precisa ser repensado é a concepção equivocada de muitos professores que trabalham com alunos do ensino fundamental e médio, que ainda mantêm a crença de que a responsabilidade do ensino da leitura é unicamente dos professores alfabetizadores.

Diante dos fatos supracitados, e por acreditarmos que é possível ensinar o leitor a construir uma leitura eficiente através de algumas estratégias, apresentamos a proposta do trabalho "Good luck or bad luck? Uma aula de leitura na tela em língua inglesa" para os trinta e cinco alunos do oitavo ano de uma escola pública em uma cidade do interior de Minas Gerais. Os alunos estudam em uma escola estadual, moram em uma cidade de cerca de 15 mil habitantes, são adolescentes (a maioria com aproximadamente 13 anos de idade). A escola conta com um laboratório de informática, mas a internet não é de boa qualidade. Em decorrência disso, baixamos o vídeo e utilizamos o Power Point, pois trabalhamos offline a fim de não dependermos unicamente da internet, reconhecendo a situação dada. Escolhemos um vídeo que tivesse apelo entre os adolescentes já que aborda temas relevantes a eles e apresenta uma atriz conhecida pelos jovens ${ }^{7}$. Já os tópicos dos textos, superstições e sorte ${ }^{8}$, são consequência do tema

\footnotetext{
${ }^{7}$ Vídeo disponível em: https://www.youtube.com/watch?v=ZnR2KrXcovM. Acesso em: 10 abr. de 2016.
} 
proposto no livro didático da série, Alive! 8, pois tomamos o cuidado de respeitar a programação curricular da professora.

Retomando o tópico sobre as estratégias de leitura, discutido na segunda parte de nosso estudo, cabe salientarmos que concebemos tais estratégias como

\begin{abstract}
habilidades usadas para promover a compreensão em situações de leitura, caracterizando-se por serem planos flexíveis que os leitores usam, adaptados às diferentes situações, variando de acordo com o texto a ser lido e o plano ou abordagem elaborada previamente pelo leitor (JOLY, 2006, online).
\end{abstract}

Fizemos uso de estratégias metacognitivas de leitura que podem ser definidas como a consciência do leitor sobre o seu nível de compreensão durante a leitura e sua habilidade para controlar suas ações cognitivas, por meio de estratégias que facilitem a compreensão de um determinado tipo de texto ou tarefa. Essas estratégias permitem ao leitor planejar, monitorar e regular o seu próprio pensamento enquanto lê (JOLY, 2006).

$\mathrm{O}$ uso de tais estratégias e as teorias acima expostas evidencia que a escola aumentará suas chances de ter sucesso na leitura, tanto em língua estrangeira quanto em língua materna, se chamar a atenção do aluno para a mesma, se ler junto com ele, ou seja, oferecer um caminho "que ele possa seguir para construir o sentido" (SANTORUM; SCHERER, 2008, p. 1). "O aluno precisa vivenciar atividades que o ajudem a lidar com o seu próprio processo de leitura, a fim de tirar melhor proveito dele", complementam Coscarelli e Cafiero (2013, p. 21).

Com o objetivo de desenvolver a leitura de textos informativos cujos títulos eram "It's bad luck to walk under a leaning ladder"e "A Black cat crossing your path is lucky/ unlucky”, traçamos algumas estratégias. Para anteciparmos informação e engajálos na discussão do tema, contextualizando o tópico da aula, exploramos ilustrações relativas a sorte/ azar/superstições ${ }^{9}$ e lançamos a seguinte pergunta - "What do they have in common?". Além disso, o leitor precisou mobilizar informações de seu conhecimento anterior, relacionando-o às figuras apresentadas. Brown (2001) acredita que os professores devem sempre tentar despertar a curiosidade dos alunos, bem como ativar seu conhecimento de mundo a fim de promover leituras significativas.

\footnotetext{
${ }^{8}$ Os textos "It's bad luck to walk under a leaning ladder" e "A black cat crossing your path is lucky/unlucky" foram retirados do site: http://www.livescience.com/33507-origins-of-superstitions.html. Acesso em: 20 jan. de 2016. Eles serão mencionados posteriormente e, também, no plano de aula.

${ }^{9}$ As ilustrações foram retiradas do Google e eram compostas por: um espelho quebrado, um gato preto, o número treze, um trevo de quatro folhas e alguém passando embaixo de uma escada.
} 
A fim de promover uma leitura eficiente, adicionamos outros recursos semióticos à leitura, pois acreditamos que no processo de ensinar a ler não devemos privilegiar apenas a parte escrita (VAN LEEUWEN, 2005), mas diversificar os gêneros textuais, os recursos semióticos e multimodais. Fizemos uso do trailer do filme "Just my luck” para que os alunos buscassem a ideia geral do vídeo. Para isso, antecipamos que eles deveriam ficar atentos às informações fornecidas pelas imagens, sons, músicas, gestos e todas as expressões apresentados no vídeo.

Posteriormente, os pares de alunos denominados A e B realizaram a leitura dos títulos: "It's bad luck to walk under a leaning ladder"e "A Black cat crossing your path is lucky/ unlucky" acompanhados de ilustrações e eles inferiram sobre qual seria o tema do texto a ser lido. Solicitamos aos alunos que levassem em consideração o título e a figura referentes ao texto e respondessem que tipo de história ele provavelmente contaria. Questionamos sobre o tipo de palavras que eles esperavam encontrar no texto; se eles precisavam entender tudo que é falado nele para chegar à ideia geral do mesmo; bem como, o que os ajudaria a entender a ideia geral. Pedimos que trocassem ideias com o colega ao lado a respeito das previsões feitas por eles.

Dando seguimento ao plano de aula, diante dos slides que continham os textos completos, solicitamos que localizassem as seguintes informações: De onde ele foi retirado? Quem é o autor? Qual é o título? O que as imagens dizem? (figura; letra maiúscula; negrito; parênteses; aspas; cores diferentes). Há palavras parecidas em português? Sublinhe-as. Nesse momento, eles também puderam verificar se as previsões que eles fizeram antes de ler o texto se confirmaram. Nuttal (1996) acredita que "a maneira que interpretamos depende do conhecimento prévio que ativamos"10 (p. 7). Daí advém a importância de prepararmos o aluno para a leitura e não simplesmente "mandálos" ler (COSCARELLI; CAFIERO, 2013). Posteriormente, foi pedido aos alunos que lessem o texto a fim de entenderem a ideia geral do mesmo. Dividimos a sala em alunos "A" e "B" aleatoriamente. Os alunos "A" leram um dos textos e os "B", o outro.

O passo seguinte foi trabalhar as palavras desconhecidas de forma contextualizada e auxiliar os alunos a compreenderem os textos, tendo em mente que o

\footnotetext{
10 Tradução nossa do inglês: "the way we interpret depends on the schemata activated by the text" (NUTTAL, 1996, p. 7).
} 
nível de proficiência dos alunos é iniciante ${ }^{11}$. Estávamos cientes da dificuldade dos alunos na leitura de textos em inglês, que já havia sido relatada pela professora, por isso, optamos por textos autênticos de extensão mais curta e gênero textual familiar, como já mencionada na parte 2 deste estudo, além de ensinarmos estratégias de leitura para oferecê-los suporte. Com aquela atividade, tínhamos o objetivo de ensinar palavras importantes ao entendimento do texto e que acreditávamos ser desconhecidas aos alunos. Solicitamos que inferissem significados das palavras dentro da frase, para que a necessidade de traduzir palavra por palavra fosse ceifada e que se evitasse a tradução literal. Posteriormente, os pares tiveram a oportunidade de conferir as previsões feitas nos slides posteriores que ofereceram ilustrações das palavras ressaltadas ${ }^{12}$.

A fim de localizar informação específica, apresentamos perguntas de compreensão do texto e demonstramos que não é preciso ler o texto todo novamente para encontrar as respostas. Depois desta atividade, alunos que leram o texto A contaram a história do mesmo aos alunos leitores do texto B e vice versa. Utilizamos para tanto, a técnica de jigsaw reading. Nuttal (1996, p. 209) define tal técnica como "aquela que envolve muita atenção ao texto, permuta oral de informações sobre ele (A precisa da informação que o B tem e vice-versa)"13. Ellis (2001, p. 78) acrescenta que

a estratégia de "quebra-cabeça", desenvolvida por Elliot Aronson, é uma combinação interessante de aprendizagem colaborativa e uma estrutura que aponta objetivos individuais. A ideia de "quebra-cabeça" é que cada aluno, em um grupo cooperativo de aprendizagem (...) é responsável por ensinar seus colegas uma parte do material que todos necessitam aprender. Assim, cada aluno ensina um terço da informação, habilidades ou qualquer outro, e é ensinado dois terços do conteúdo ${ }^{14}$.

Assim, a estratégia de jigsaw reading cria uma necessidade da fala na aula de leitura, já que os alunos trabalham de modo colaborativo. Ela ainda auxilia o aluno a ser capaz de ler e depois resumir o texto de modo que seus colegas o entendam. Tal técnica

\footnotetext{
${ }^{11}$ É o terceiro ano de estudos da língua inglesa nessa escola.

12 Um exemplo é: "It's bad luck to walk under a leaning ladder" em que associamos a expressão sublinhada com a figura correspondente a ela.

13 Tradução nossa do inglês: "a technique that involves close attention to text, oral exchange of information (A needs information that B has, and vice-verse)" (NUTTAL, 1996, p. 209).

14 Tradução nossa do inglês: "The jigsaw strategy, developed by Elliot Aronson, is an interesting combination of cooperative learning with an individualistic goal structure. The idea of jigsaw is that each student in a cooperative learning group (...) is responsible for peer teaching his/her companions a portion of the material they all need to learn. Thus each student teaches one-third of the information, skills, or whatever, and is taught two-thirds of the content" (ELLIS, 2001, p. 78).
} 
auxilia o aluno médio ou mesmo aquele mais tímido, já que ele aprende com os colegas, de uma maneira mais confortável e próxima. A professora da turma em que a aula foi dada se surpreendeu muito com a participação dos alunos e acreditamos que essa técnica é uma das responsáveis por estimular essa participação intensa. Além disso, oferecemos expressões, em inglês, para que os alunos pudessem se guiar por elas para formar frases e se motivarem a falar em inglês ${ }^{15}$.

Desse modo, priorizamos a leitura na aula em questão, mas garantimos espaço para o desenvolvimento das habilidades de escuta e da fala. Ao que Paiva (2005, p. 147) advoga que "o foco apenas na leitura trata a língua como uma língua morta, como se sua manifestação fosse restrita a registros escritos”. Brown (1994, p. 357) acrescenta ainda que,

a habilidade de leitura será melhor desenvolvida associada com atividades de escrita, escuta e fala. Mesmo naqueles cursos que podem ser rotulados de "cursos de leitura", seus objetivos serão alcançados de maneira melhor a partir da capitalização da inter-relação das habilidades16.

Cabe ressaltar aqui como foi o processo de construção do sentido dos textos, ou seja, como a coerência do texto foi trabalhada. Os textos, como nos conta Marcushi (2005), se apresentam com insuficiência de explicitude e cabe ao leitor construir e dar sentido ao mesmo. O leitor não é o único responsável pela construção deste sentido, mas ele pode dirigir a construção do sentido.

Lembrando que língua em nossa concepção não nega a presença do sistema, mas não o considera ponto de partida e chegada (MARCUSHI, 2005), exploramos os textos do nosso trabalho através de estratégias de leitura, a fim de conduzir o aluno-leitor à construção de sentido do texto, mas este processo não desprezou a forma da língua.

Enfim, corroborando as ideias de Beaugrande (1997 apud MARCUSHI 2005), "é essencial tomar o texto como um evento comunicativo no qual convergem ações linguísticas, cognitivas e sociais" (p.10), acreditamos que os alunos do nosso estudo, ao construírem a coerência do texto, passaram por todas estas ações.

\footnotetext{
${ }^{15}$ Alguns exemplos de frases são: "In my view... / To my mind... / As I see it... / According to the text... / The text is interesting because...

${ }^{16}$ Tradução nossa do inglês: Reading ability will best be developed in association with writing, listening, and speaking activity. Even in those courses that may be labelled "reading", your goals will be best achieved by capitalizing on the interrelationship of skills (BROWN, 1994, p. 357).
} 
$\mathrm{Na}$ etapa pós-leitura, oportunizamos uma reação e uma personalização dos alunos ao conteúdo dos textos trabalhados e ativamos a sua habilidade de produção oral, propondo a discussão das questões -“O que é ser sortudo? Vocês são sortudos? Por quê?"17 Finalmente, apresentamos uma charge do personagem Chico Bento e questionamos sobre qual mensagem ela transmitia e se eles concordavam e por qual razão.

Estendemos o trabalho de leitura, na qualidade de "tarefa de casa", remetendo os alunos ao livro didático Alive! 8, adotado pela escola, solicitando a eles que escolhessem duas charges da página 24 do livro e dissessem ao colega o que eles entenderam e a razão pela qual fizeram determinada escolha. Essa atividade visou criar um entrosamento entre as atividades desenvolvidas e o livro didático usado pela escola.

Cada gênero textual usado em nossa atividade de estudo cumpriu com eficiência sua função. Enquanto os textos autênticos relativos a sorte e superstições esclareceram sobre a origem da superstição abordada, o vídeo apresentou de forma sucinta o resumo do filme, relacionado ao tema e atendeu o seu objetivo de entretenimento e informação. A charge cumpriu efetivamente a sua função de realizar uma crítica através do humor. Quanto ao design das imagens contribuiu muito para aproximar o leitor e dar sentido ao texto, caracterizando-se como um recurso semiótico que promove sentido ao texto.

Ao levarmos um trailer de um filme de comédia romântica para a sala, charges e promovermos a maximização da participação dos alunos buscamos aliar o pedagógico ao lúdico. Coscarelli (2010), embasada nas ideias de Araújo (2007), aponta que um dos grandes problemas das atividades de letramento digital é o abismo que há entre as atividades realizadas na escola e em casa. Em outros termos, em casa o aluno pode utilizar redes sociais, ver vídeos, jogar, por exemplo, na escola, seu acesso limita-se a atividades controladas, muitas vezes, sem entretenimento.

Quanto aos textos escritos que projetamos em slides do Power Point, vimos que o material impresso inclui textos tão ilustrados como os por nós apresentados na tela, mas quando nos referimos ao vídeo, constatamos que o meio digital proporcionou som, imagem, movimento e tantos outros efeitos possibilitados por tecnologias modernas

\footnotetext{
${ }^{17}$ Concebemos as perguntas em inglês, mas no correr da aula, elas foram feitas em português, por isso as colocamos em português aqui e no plano de aula.
} 
como o computador, motivando os alunos a explorá-los e tornando-se familiar aos mesmos.

Além disso, a proposta apresenta-se como uma forma de interação e pode ser muito significativa para o aluno, que precisa desenvolver estratégias de leitura a fim de se tornar um leitor eficiente. O uso do computador é motivador para o adolescente, pois é uma mídia familiar e, ao mesmo tempo, fascinante para ele. A aula promoveu também a saída da rotina, já que permitiu que os alunos saíssem de sua sala habitual e utilizassem o laboratório de informática, outrora pouco utilizado nas aulas de língua inglesa, segundo a professora da turma.

Pontuamos que a aula se constitui o início de um processo que sempre carece de completude. Segundo Paulino (2011, p. 219), a formação de leitores caracteriza-se por "um processo ininterrupto: mudam-se os textos, mudam-se os suportes, mudam-se as condições de leitura, mudam-se os interesses e as prioridades dos leitores, por isso a formação tem que ser contínua”. É premente, pois, que o trabalho com a leitura, seja na tela ou papel, tenha caráter processual, do mesmo modo que se torna necessária a reciclagem das estratégias de leitura não somente nas aulas de inglês, mas em todas as aulas cujo objetivo é auxiliar os alunos a lerem de modo mais eficiente.

\section{FEEDBACK DA PROFESSORA E DOS ALUNOS ACERCA DO QUE PENSAM} SOBRE A AULA

De acordo com os dados obtidos através dos questionários respondidos ${ }^{18}$ por vinte oito alunos da classe (do total de 35), quatorze deles declararam nunca terem participado de aula semelhante à proposta e dezenove destes alunos a consideraram mais interessante do que a maioria das aulas de leitura que eles já tiveram. Quatorze alunos pontuaram que o elemento que torna a aula mais interessante é o fato de a leitura ser no computador, enquanto vinte e oito alunos reportaram que a aula foi uma saída da rotina.

\footnotetext{
${ }^{18}$ Foram confeccionados dois questionários: um para a professora e um para os alunos. Ambos os questionários investigavam tempo de estudo/ensino da língua inglesa, interesse pela mesma, e aspectos concernentes ao ensino/aprendizagem da leitura em língua inglesa (facilidade, frequência, interesse...) e finalmente, perguntávamos sobre aspectos da aula dada (se haviam gostado da aula, se haviam tido/dado aulas semelhantes a essa, se as estratégias haviam sido úteis, se pretendiam continuar utilizandoas/ensinando-as, entre outras).
} 
Estes dados foram confirmados pela resposta da professora da sala a um questionário com perguntas específicas sobre o trabalho dela com leitura, pois esta confirmou que raramente faz uso de tecnologias digitais para trabalhar com a leitura e quando as utiliza, faz uso de data show, embora considere que o uso das tecnologias digitais possa colaborar para a formação do aluno-leitor e que a tela traz mudanças significativas nas formas de interação entre escritor e leitor.

A professora acredita que as estratégias de leitura, exploradas em nosso trabalho, facilitaram a compreensão dos textos em inglês, o que coincide com a opinião de vinte e dois alunos da classe. Vinte e três alunos declararam pretender utilizar as estratégias de leitura ensinadas em outros textos em inglês ou em outra língua e quinze deles afirmaram estarem mais motivados a ler textos em inglês, tanto na tela quanto no papel, após a nossa aula.

Quanto à compreensão do texto, apesar da professora normalmente fazer uso de dicionários em sala de aula e contar com a interação entre colegas e entre alunoprofessora para esclarecer dúvidas, ela fazia pouco uso das novas tecnologias e das estratégias de leitura anteriormente. Depois da pesquisa, a professora mostrou-se mais inclinada a utilizar o laboratório de informática mais vezes e pedir que os alunos utilizem a internet em casa como forma de maximizar a aprendizagem.

\section{CONSIDERAÇÕES FINAIS}

Segundo Coscarelli (2010, p. 524), a escola necessita de projetos e pesquisa ${ }^{19}$ a fim de "lhe oferecer apoio, auxiliando, assim, a reflexão sobre a melhor forma de usar as novas tecnologias como recurso didático e sobre como a escola pode ajudar seus alunos a desenvolver competências e habilidades importantes para o letramento digital". Desse modo, a ideia de se trabalhar a leitura em tela constitui-se inovadora, no contexto pesquisado, visto que, apesar de, muitas vezes, bem equipadas, as escolas ainda utilizam pouco os computadores, na medida em que os professores ainda se sentem amedrontados diante deles (Ibid., 2010). A professora participante corrobora esta ideia, ao relatar que raramente utilizava as tecnologias digitais nas aulas de língua inglesa e, principalmente, nas de leitura.

\footnotetext{
${ }^{19}$ Uma das autoras desse artigo teve, como tema de sua dissertação de mestrado, o letramento digital, e realizou sua coleta de dados na escola pública em questão.
} 
Acreditamos que outra inovação foi aliar a aula de leitura a outras habilidades e utilizar a técnica do jigsaw reading que abre espaço para que os alunos tenham um posicionamento ativo em sala de aula. O ensino de estratégias constituiu-se em uma inovação também, uma vez que em muitas aulas de leitura o aluno não é ensinado a ler, somente executa a ação (COSCARELLI; CAFIERO, 2013).

As contribuições ocorreram em vários níveis. Primeiramente, de acordo com os questionários, tornou a aula de leitura motivadora e fundante de atitudes de leitura. Em outros termos, $54 \%$ dos alunos relataram se sentirem mais motivados a lerem tanto no papel quanto em tela. Em relação ao uso de estratégias, $82 \%$ relataram que pretendem utilizar as estratégias ensinadas não só com outros textos em inglês, mas também em outras línguas. Como a formação de leitores tem caráter processual, pedimos à professora para reciclar tais estratégias sempre que trabalhar com textos.

Parece ter havido uma contribuição substancial para derrubar a concepção que, muitas vezes, predomina em relação ao modo como a escola trabalha a leitura: de maneira chata; obrigatória; utilitarista e sem contemplar todos os tipos de aprendizes. Aliamos o lúdico ao pedagógico, oferecendo a leitura como uma atividade prazerosa, passível de ser aprendida. $50 \%$ dos alunos pontuaram que nunca haviam participado de uma aula semelhante a essa e $80 \%$ que gostou da aula por ela apresentar uma fuga da rotina.

Apesar da escola não ser mais o único lugar de legitimação do saber, ela ainda "ocupa um dos espaços de formação dos leitores, mas tem que trabalhar com os diferentes suportes do impresso e com as diversas telas". (FREITAS, 2011, p. 215). Desse modo, é preciso contemplar a leitura na escola como uma habilidade cognitiva, ensinável e na qualidade de algo que precisa ser motivante, prazerosa e processual. Além disso, "formar o leitor de livros e telas é ampliar o repertório disponível. Sobretudo, é deixar que o leitor viva a experiência de se inserir neles e se transformar" (Ibid., p. 215).

\section{REFERÊNCIAS}

ARAÚJO, J. C. Internet \& Ensino: novos gêneros, outros desafios. Rio de Janeiro: Lucerna, 2007. 
BARROS, C. G. P. Capacidades de leitura de textos multimodais. In: Polifonia. Cuiabá: Editora EDUFMT, p. 161-186, 2009.

BRÄKLING, K. L. Sobre a leitura e a formação de leitores: Qual é a chave que se espera? São Paulo: SEE: Fundação Vanzolini, 2004. Texto parcialmente publicado no portal www.educarede.org.br.

BROWN, H. D. Teaching by Principles. New York: Longman, 2001.

COSCARELLI, C. V. A cultura escrita na sala de aula (em tempos digitais). In: MARINHO, M; CARVALHO, G. T. (org.). Cultura escrita e letramento. Belo Horizonte: Editora UFMG, 2010, p. 513-526.

COSCARELLI, C. V.; CAFIERO, D. Ler e ensinar a ler. In: COSCARELLI, C. V. (org.). Leituras sobre a leitura: passos e espaços na sala de aula. Belo Horizonte: Vereda, 2013, p. 9-35).

ELLIS, A. K. Teaching learning and assessment together: reflective classroom. New York: Eye on Education, 2001.

FREITAS, M. T. A. A tela e o livro: um diálogo possível? In: MARTINS, A. A. et al (org). Livros \& Telas. Belo Horizonte: Editora UFMG, 2011, p. 202-217.

JOLY, M. C. R. A.; SANTOS, L. M.; MARINI, J. A. S. Uso de estratégias de leitura por alunos do Ensino Médio. 2006. Acesso em: 15 de maio de 2014. Disponível em: http://sites.ffclrp.usp.br/paideia/artigos/34/08.htm.

KLEIMAN, A. B. Abordagens de leitura. In: Scripta. Belo Horizonte, v. 7, n. 14, p 1322, primeiro semestre de 2004.

MARCUSCHI , L. A. A coerência no Hipertexto. In: COSCARELLI, C.; RIBEIRO, A. E. Letramento digital: aspectos sociais e possibilidades pedagógicas. Belo Horizonte: Ceale; Autêntica, 2005.

NUTTAL, C. Teaching Reading Skills in a foreign language. Oxford: Macmillan Heinemann, 1996.

PAIVA, V. L. M. O. Desenvolvendo a habilidade de leitura In: PAIVA, V. L. M. O. (Org.). Práticas de ensino e aprendizagem de inglês com foco na autonomia. Belo Horizonte: Faculdade de Letras da UFMG, 2005. p. 129-14.

PAIVA, V. L. M. O.; BRAGA, J.; FRANCO, C. Alive! 8. 2012. Acesso em 05 de maio de 2014. Disponível em: www.veramenezes.com.

PAULINO, G. O acesso a impressos e à internet na formação de leitores. In: MARTINS, A. A. et al (org.). Livros \& Telas. Belo Horizonte: Editora UFMG, 2011, p. 218-225. 
RIBEIRO, A. E. A importância do design na leitura. In: COSCARELLI, C. V. (org). Leituras sobre a leitura: passos e espaços na sala de aula. Belo Horizonte: Vereda, 2013, p. 61-87.

SANTORUM, K.; SCHERER, L. C. O papel do ensino de estratégias para o desenvolvimento da leitura em segunda língua (L2). In: ReVEL. Vol. 6, n.11, agosto de 2008.

SOARES, M. B. Práticas de letramento e implicações para a pesquisa e para as políticas de alfabetização e letramento. In: MARINHO, M.; CARVALHO, G. T. (org.). Cultura e letramento. Belo Horizonte: Editora UFMG, 2010, p. 54- 67.

VAN LEEUWEN, T. Introducing social semiotics. London: Routledge. 2005.

\section{APÊNDICES}

\section{PLANO DE AULA DE LEITURA EM TELA}

\section{Dados da aula}

Data: 06/05/2016

Número de alunos: 35 Série: Oitavo ano Duração da aula: 50 minutos

Objetivos: Engajar os alunos na leitura em tela buscando motivá-los a serem leitores mais eficientes através das estratégias de leitura.

Evidência: Nossos objetivos serão atingidos se os alunos se engajarem nas atividades oferecidas bem como se fornecerem um feedback positivo no questionário a ser aplicado posteriormente.

Objetivos de pesquisa: Inovar no ensino de leitura; motivar os alunos a lerem mais e a usarem estratégias de leitura para fazê-lo de maneira mais proveitosa e eficiente.

\section{Contexto}

Perfil dos alunos: O grupo é composto por 35 alunos de uma escola estadual em uma pequena cidade do interior de Minas Gerais. São adolescentes com aproximadamente 13 anos de idade. A professora de inglês está com o grupo desde o começo do semestre letivo de 2014. Esse é o terceiro ano de língua inglesa deles na escola, porém o primeiro ano que utilizam a coleção Alive! Estão estudando pelo livro Alive! 8.

Objetivos de aprendizagem: Contribuir para a formação de um leitor mais competente em língua inglesa, já com vistas ao ENEM, vestibular, concursos. 
Antecipação de problemas: Alguns alunos podem acreditar que não é possível depreender nenhum significado dos textos por estarem em inglês. Porém, através das estratégias de leitura pretendemos oferecer a eles uma nova forma de se enxergar e se comportar diante de um texto em inglês. Acreditamos que isso é um processo, assim, a ideia é que essa aula seja seguida de outros textos que tenham a intenção de formar leitores mais eficientes e proficientes.

Habilidades de linguagem: Leitura; Fala; Escuta

Vocabulário específico: black cat; four leaf clover; thirteen; leaning ladder; broken mirror; good luck/bad luck/superstition; I'm (not) lucky!

\section{Tópico-contexto: Sorte/ Superstições}

Material: Computador/ Laboratório de informática; Power Point/ You Tube; Livro do aluno: Alive! 8 (PAIVA, V. L. M. O.; BRAGA, J.; FRANCO, C. 2012, pág. 24); Site:http://www.livescience.com/33507-origins-of-superstitions.html

Plano da próxima aula: $\mathrm{Na}$ próxima aula, o professor abordará o tópico de superstições, mas a partir do livro didático Alive! 8, página 24. Ele relembrará as estratégias de leitura utilizadas na presente aula para que os alunos leiam as outras duas charges que não estavam na tarefa.

\begin{tabular}{|c|c|c|c|c|c|}
\hline Passo & Objetivo & Atividade / Procedimento & $\begin{array}{l}\text { Tipo de } \\
\text { intera- } \\
\text { ção }\end{array}$ & Material & $\begin{array}{c}\text { Dura } \\
\text { ção }\end{array}$ \\
\hline $\begin{array}{c}\text { 1) } \\
\text { Engajamento }\end{array}$ & $\begin{array}{l}\text { - Ativar } \\
\text { conhecimento } \\
\text { prévio sobre o } \\
\text { tópico. } \\
\text { - Engajar os } \\
\text { alunos na } \\
\text { discussão. } \\
\text {-Contextualizar } \\
\text { o tópico da } \\
\text { aula. }\end{array}$ & $\begin{array}{c}\text { - Mostrar aos alunos figuras } \\
\text { relacionadas à sorte. O professor } \\
\text { as nomeia em inglês e pergunta: } \\
\text { O que essas figuras têm em } \\
\text { comum? Alunos discutem em } \\
\text { pares } \\
\text { - Então, qual será o tópico da } \\
\text { aula de hoje? } \\
\text { - Nós estudaremos não só as } \\
\text { superstições, mas a origem delas }\end{array}$ & $\begin{array}{l}\text { Professor } \\
\text { Aluno- } \\
\text { aluno } \\
\text { Professor }\end{array}$ & $\begin{array}{c}\text { - Apresentação no } \\
\text { Power Point no } \\
\text { computador }\end{array}$ & $4^{\prime}$ \\
\hline $\begin{array}{l}\text { Video - 2) Pré- } \\
\text { leitura/leitura }\end{array}$ & $\begin{array}{l}\text { - Preparar os } \\
\text { alunos para as }\end{array}$ & $\begin{array}{l}\text { - O professor fará uso do trailer, } \\
\text { em inglês, do filme “Just my } \\
\text { luck" (Sorte no amor, no Brasil). }\end{array}$ & & - Computador/ & \\
\hline
\end{tabular}


REVISTA X, Curitiba, volume 12, n.3, p.131-151,2017.

\begin{tabular}{|c|c|c|c|c|c|}
\hline & $\begin{array}{l}\text { leituras } \\
\text { posteriores. } \\
\text { - Iniciar a } \\
\text { apresentação de } \\
\text { estratégias de } \\
\text { leitura. }\end{array}$ & $\begin{array}{l}\text {-Antes de exibi-lo, mostrar o } \\
\text { título e a capa do filme fazendo } \\
\text { algumas perguntas para a turma: } \\
\text { a) O título do vídeo é "Just } \\
\text { my luck" (Sorte no } \\
\text { amor, no Brasil). Que } \\
\text { tipo de história ele deve } \\
\text { contar? Quais palavras } \\
\text { vocês esperam } \\
\text { encontrar nele? } \\
\text { b) Vocês precisam } \\
\text { entender tudo que é } \\
\text { falado no vídeo para } \\
\text { chegar à ideia geral do } \\
\text { mesmo? } \\
\text { c) O que os ajudará a } \\
\text { entender a ideia geral? } \\
\text { (imagens; gestos). } \\
\text { - Após assistirem o vídeo, } \\
\text { elencar o que compreenderam e } \\
\text { o que os ajudou a entender a } \\
\text { mensagem. Podem trabalhar em } \\
\text { pares e depois com a turma toda. } \\
\text { (O professor falará que o } \\
\text { objetivo é ver o vídeo e entender } \\
\text { a ideia geral do mesmo). }\end{array}$ & $\begin{array}{l}\text { Aluno- } \\
\text { aluno } \\
\text { Professor }\end{array}$ & $\begin{array}{l}\text { You tube: } \\
\text { http://www.youtub } \\
\text { e.com/watch?v=rk } \\
\text { JInkePtOY } \\
\text { - Vídeo: “Just my } \\
\text { luck" 2'10" }\end{array}$ & 5 \\
\hline $\begin{array}{l}\text { Texto escrito } \\
\text { 3) Pré-leitura } 2\end{array}$ & $\begin{array}{l}\text {-Explorar } \\
\text { estratégias de } \\
\text { leitura }\end{array}$ & $\begin{array}{l}\text { - Os pares de alunos são } \\
\text { denominados A e B. Os alunos } \\
\text { A lerão o texto: "It's bad luck to } \\
\text { walk under a leaning ladder". } \\
\text { Ao passo que os aluno B lerão o } \\
\text { texto: "A black cat crossing your } \\
\text { path is lucky/unlucky". } \\
\text { - Levando em consideração o } \\
\text { título e a figura referentes ao } \\
\text { texto: } \\
\text { a)Que tipo de história ele deve } \\
\text { contar? Quais palavras vocês } \\
\text { esperam encontrar nele? } \\
\text { b) Vocês } \\
\text { entender tudo que é falado no } \\
\text { vídeo para chegar à ideia geral } \\
\text { do mesmo? } \\
\text { c) O que os ajudará a } \\
\text { entender a ideia geral? Resposta } \\
\text { em pares. }\end{array}$ & $\begin{array}{l}\text { Aluno- } \\
\text { aluno }\end{array}$ & $\begin{array}{l}\text { - Apresentação no } \\
\text { Power Point no } \\
\text { computador }\end{array}$ & 7 \\
\hline
\end{tabular}


REVISTA X, Curitiba, volume 12, n.3, p.131-151,2017.

\begin{tabular}{|c|c|c|c|c|c|}
\hline & & $\begin{array}{l}\text { - Utilizar o texto em si. Resposta } \\
\text { em pares } \\
\text { a) De onde ele foi retirado? } \\
\text { b) Quem é o autor? } \\
\text { c) Qual é o título? } \\
\text { d) O que as imagens nos dizem? } \\
\text { (figura; letra maiúscula; negrito; } \\
\text { parênteses; aspas; cores } \\
\text { diferentes) } \\
\text { e) Há palavras parecidas em } \\
\text { português? Sublinhe-as. }\end{array}$ & $\begin{array}{l}\text { Aluno- } \\
\text { aluno }\end{array}$ & & \\
\hline $\begin{array}{l}\text { 4) Leitura } \\
\text { (ideia geral) }\end{array}$ & $\begin{array}{l}\text { - Conferir se as } \\
\text { previsões } \\
\text { estavam } \\
\text { corretas } \\
\text { - Ler para } \\
\text { entender a ideia } \\
\text { geral }\end{array}$ & $\begin{array}{l}\text { - Alunos lêem o texto fazendo } \\
\text { uso das estratégias (relembrá-los } \\
\text { das utilizadas com o vídeo } \\
\text { também). O objetivo é entender } \\
\text { a ideia geral para, } \\
\text { posteriormente, reportá-la ao } \\
\text { colega que leu outro texto. }\end{array}$ & $\begin{array}{c}\text { Professor } \\
\begin{array}{c}\text { Aluno- } \\
\text { aluno }\end{array}\end{array}$ & $\begin{array}{l}\text { - Apresentação no } \\
\text { Power Point no } \\
\text { computador }\end{array}$ & $5^{\prime}$ \\
\hline $\begin{array}{c}\text { 5)Ensino do } \\
\text { vocabulário } 2\end{array}$ & \begin{tabular}{|l|} 
- Trabalhar \\
palavras \\
desconhecidas \\
de forma \\
contextualizada \\
e auxiliar os \\
alunos a \\
compreender os \\
textos \\
-Inferir \\
significados \\
das palavras \\
dentro da frase
\end{tabular} & $\begin{array}{l}\text { - O professor apresenta quatro } \\
\text { frases, referentes ao seu texto, } \\
\text { para cada dupla. As palavras- } \\
\text { alvo estão em negrito e } \\
\text { sublinhadas. Em pares, os alunos } \\
\text { tentaram inferir o significado das } \\
\text { mesmas através do contexto. } \\
\\
\text { - Posteriormente, os pares } \\
\text { conferem suas previsões nos dois } \\
\text { próximos slides que oferecem } \\
\text { sejam figuras ou o significado } \\
\text { em português das palavras. }\end{array}$ & $\begin{array}{l}\text { Professor } \\
\text { Aluno- } \\
\text { aluno } \\
\begin{array}{c}\text { Aluno- } \\
\text { aluno }\end{array}\end{array}$ & $\begin{array}{l}\text { - Apresentação no } \\
\text { Power point no } \\
\text { computador }\end{array}$ & $5^{\prime}$ \\
\hline $\begin{array}{l}\text { 6) Leitura } \\
\text { (conhecimento } \\
\text { específico) }\end{array}$ & \begin{tabular}{|l|} 
- trabalhar o \\
conhecimento \\
detalhada \\
através de \\
perguntas sobre \\
o textos \\
\\
-demonstrar \\
que não é \\
preciso ler o \\
texto todo
\end{tabular} & $\begin{array}{l}\text { - O professor pede para que os } \\
\text { alunos respondam, em pares, a } \\
\text { duas perguntas sobre o texto } \\
\text { lido: } \\
\text { Texto A } \\
\text { a) Why is it bad luck to walk } \\
\text { under a leaning ladder? b) Why } \\
\text { did the text mention Jesus } \\
\text { Christ? } \\
\text { Texto B }\end{array}$ & $\begin{array}{l}\text { Professor } \\
\begin{array}{c}\text { Aluno- } \\
\text { aluno }\end{array}\end{array}$ & & $5^{\prime}$ \\
\hline
\end{tabular}


REVISTA X, Curitiba, volume 12, n.3, p.131-151,2017.

\begin{tabular}{|c|c|c|c|c|c|}
\hline & $\begin{array}{l}\text { novamente para } \\
\text { encontrar as } \\
\text { palavras no } \\
\text { texto }\end{array}$ & $\begin{array}{l}\text { a) Why is it bad luck if a cat } \\
\text { crosses your path? b) Was it } \\
\text { always considered bad luck? } \\
\text { Why not? } \\
\text { - Os alunos respondem } \\
\text { oralmente e em pares. } \\
\text { Professora monitora os alunos } \\
\text { para auxiliar com possíveis } \\
\text { dúvidas. }\end{array}$ & & $\begin{array}{l}\text { - Apresentação no } \\
\text { Power Point no } \\
\text { computador }\end{array}$ & \\
\hline $\begin{array}{l}\text { 7) Jigsaw } \\
\text { reading }\end{array}$ & $\begin{array}{l}\text { - verificar } \\
\text { entendimento } \\
\text { do texto e } \\
\text { dinamizar a } \\
\text { leitura do texto } \\
\text { - auxiliar os } \\
\text { alunos mais } \\
\text { fracos na } \\
\text { compreensão } \\
\text { do texto } \\
\text { - trabalhar a } \\
\text { habilidade de } \\
\text { resumir textos }\end{array}$ & $\begin{array}{l}\text { - Alunos que leram o texto A } \\
\text { contam a história do mesmo aos } \\
\text { alunos leitores do texto B e vice } \\
\text { versa. } \\
\text { - O professor pede para que um } \\
\text { par que leu o texto A, o reporte } \\
\text { para a turma realizando o mesmo } \\
\text { procedimento com os alunos que } \\
\text { leram o texto B. }\end{array}$ & $\begin{array}{l}\text { Aluno- } \\
\text { aluno }\end{array}$ & & $5^{\prime}$ \\
\hline 8) Pós leitura & $\begin{array}{l}\text { - oportunizar } \\
\text { uma reação e } \\
\text { uma } \\
\text { personalização } \\
\text { dos alunos ao } \\
\text { conteúdo dos } \\
\text { textos } \\
\text { trabalhados }\end{array}$ & $\begin{array}{l}\text { - O professor pergunta aos } \\
\text { alunos: O que é ser sortudo? } \\
\text { Vocês são sortudos? Por quê? Os } \\
\text { alunos respondem às perguntas } \\
\text { em pares. } \\
\text { - Leiam a charge do Chico } \\
\text { Bento. What's the message? } \\
\text { (Qual mensagem ela transmite?). } \\
\text { Do you agree? Why? (Você } \\
\text { concorda? Por quê?). } \\
\text { Respondem em pares e depois, a } \\
\text { turma toda. }\end{array}$ & $\begin{array}{c}\text { Professor } \\
\begin{array}{c}\text { Aluno- } \\
\text { aluno } \\
\text { Professor } \\
\text { Aluno- } \\
\text { aluno }\end{array}\end{array}$ & $\begin{array}{l}\text { - Charge do Chico } \\
\text { Bento }\end{array}$ & $5^{\prime}$ \\
\hline $\begin{array}{l}\text { 9) Tarefa de } \\
\text { casa }\end{array}$ & $\begin{array}{l}\text { - Estender o } \\
\text { trabalho de } \\
\text { leitura }\end{array}$ & $\begin{array}{l}\text { - Escolha duas charges de seu } \\
\text { livro e diga ao seu colega o que } \\
\text { você entendeu e o porquê de sua } \\
\text { escolha. }\end{array}$ & & $\begin{array}{l}\text { Livro do aluno: } \\
\text { Alive! } 8 \text { (pág. 24) }\end{array}$ & $3^{\prime}$ \\
\hline
\end{tabular}

